\title{
Breed-specific lipid-related gene expression in the subcutaneous fat of Large White and Erhualian pigs at weaning
}

\author{
Y. Zheng, S. Pan, Y. Huang, L. Ci, R. Zhao, and X. Yang \\ Key Laboratory of Animal Physiology and Biochemistry, Nanjing Agricultural University, Nanjing, China \\ Correspondence to: X. Yang (yangxj@njau.edu.cn)
}

Received: 22 November 2013 - Accepted: 24 September 2014 - Published: 4 March 2015

\begin{abstract}
The Erhualian (EHL) pig possesses significantly lower growth rates and higher adipose deposition compared with the Large White (LW) pig. To further understand the mechanism of breed lipid deposition difference at the early postnatal age, we employed an animal model of EHL and LW pigs at weaning age to compare the lipid metabolism differences in subcutaneous fat. The result showed that serum triglyceride in EHL was significantly higher $(P<0.05)$ than that of LW. Peroxisome proliferator-activated receptor- $\gamma$ protein level in EHL was significantly higher $(P<0.01)$ though CCTTA enhancer-binding protein level demonstrated no change compared with LW pigs. Hormone sensitive lipase, adipose tissue triglyceride lipase mRNA expression and the lipase activity were significantly lower $(P<0.05)$ in EHL. Uncoupling protein-2 protein content was significantly lower $(P<0.01)$ in EHL than that in LW pigs. We first cloned the nucleotide sequence of Zinc- $\alpha 2$-glycoprotein (ZAG) with $1090 \mathrm{bp}$ and found that both ZAG mRNA expression and protein level in EHL pigs was significantly lower $(P<0.01)$ than that of LW pigs. $\beta 3$ adrenergic receptor mRNA expression in EHL pigs was significantly higher $(P<0.01)$ than that of LW pigs, though tumour necrosis factor $\alpha$ gene expression demonstrated no significant difference. Therefore, the significant breed lipid metabolism difference in subcutaneous fat exists at an early postnatal age between EHL and LW pigs, and this difference may originate from two causes including the increased lipid synthesis and reduced lipid mobilization in EHL pigs compared with LW pigs.
\end{abstract}

\section{Introduction}

In recent years, an epidemic of obesity has been observed around the world. Adipose metabolism has received much attention because substantial adipose deposition is related to many metabolic diseases such as diabetes, hypertension, etc. Furthermore, it was estimated that the genetic basis for obesity could approximately range from 40 to $70 \%$ (Singla et al., 2010). The pig is one of the most important domestic species for meat production and is also an ideal model for metabolic studies including obesity (Spurlock et al., 2008). Concerning the breed specific adipose metabolism, though there have been some reports demonstrating the breed differences (Quintanilla et al., 2002; Li et al., 2008a, b; Nakajima et al., 2011; Wei et al., 2011), most of them were interested in the pigs' metabolism at the finishing period. Actually, early life is a critical period for body lipid deposition
(Wells, 2007). After birth, the adipose tissue expansion takes place rapidly as a result of increased fat cell size as well as an increase in fat cell number (Gregoire et al., 1998). Therefore, understanding the adipose metabolism at the early postnatal stage is also decisive for clarifying the breed difference of lipid deposition in pigs.

Fat metabolism mainly includes adipogenesis and lipolysis. CCTTA enhancer-binding protein $(\mathrm{C} / \mathrm{EBP} \beta)$ and peroxisome proliferator-activated receptor $\gamma(\operatorname{PPAR} \gamma)$ are well-established key transcription factors for adipogenesis. PPAR $\gamma$ is highly expressed and essentially required for the formation, differentiation and survival of adipose tissue in vivo (Koh et al., 2009). C/EBP $\beta$ is an important factor that causes adipogenesis and plays a dual role as a stimulator of cell determination and differentiation (Darlington et al., 1998). Lipolysis depends most on adipose tissue triglyceride lipase (ATGL) and hormone sensitive lipase (HSL). ATGL 
could catalyse the initial step of the triglyceride's hydrolysis (Schweiger et al., 2006). HSL is highly expressed in adipocytes, and lipolysis is influenced by its protein content, activity and the distribution in the cells (Granneman et al., 2007). For the fat utilization, carnitine palmitoyl transferaseI (CPT1) is a limited enzyme of fatty acid $\beta$-oxidation and uncoupling protein-2 (UCP2) plays a critical role in the biological traits of animal body weight, basal metabolic rate and energy conversion ( $\mathrm{Li}$ et al., 2007). Whether these lipid metabolism genes play a role in breed differences at early postnatal age in pigs is not clear.

In the past 20 years, it has been recognized that adipose tissue produces a large number of cytokines which are termed "adipokines". These adipokines have an autocrine function on adipose tissue homeostasis and they are secreted into the peripheral circulation with a systemic effect on metabolic events (Guerre-Millo, 2004; Fantuzzi et al., 2005). Recently, observations demonstrated that Zinc- $\alpha 2$-glycoprotein (ZAG) exists in both white and brown adipose tissue (Bing et al., 2004; Mracek et al., 2010) and the expression of ZAG is inversely related to the mass of white adipose tissue (Dahlman et al., 2005; Rolli et al., 2007). It has been found that ZAG could bound to $\beta 3$ adrenergic receptors ( $\beta 3$-AR) and could activate GTP-dependent adenylate cyclase to elevate intracellular cAMP level and HSL activity (Russell et al., 2002, 2004). Additionally, tumour necrosis factor $\alpha(\mathrm{TNF} \alpha)$ causes a dose-dependent decrease of ZAG expression (Bao et al., 2005). However, until now, studies on ZAG have been restricted to humans and rats, and no results have been observed in pigs. Whether it is expressed in adipose tissue of pigs and whether it is differently expressed in the two breeds is unknown.

Erhualian (EHL), a famous Chinese indigenous pig breed, belongs to the same family as Meishan, which is characterized by high reproductive rates and superior meat quality. Compared with Large White pigs (LW), EHL pigs possess significantly lower growth rate and higher adipose deposition. Though previous studies have shown the cellular difference of adipocyte in subcutaneous fat (Nakajima et al., 2011) and the quantitative trait locus (QTL) analysis of growth and fatness data between growing Landrace and Meishan pigs (Quintanilla et al., 2002; Wei et al., 2011), the adipose metabolism difference at the early postnatal stage is still largely unclear between these two breeds.

Therefore in the present study we employed LW and EHL pigs as animal models and detected the expression of lipogenesis-related genes, including PPAR $\gamma$ and $\mathrm{C} / \mathrm{EBP} \beta$, lipolysis-related genes, including HSL and ATGL, fatty acid oxidation-related genes, including CPT1 and UCP2 and the adipokine ZAG, to compare the difference in subcutaneous fat between LW and EHL pigs at weaning age. The results will shed new light on the difference in lipid metabolism of different pig breeds.

\section{Material and methods}

Six male piglets from three litters (two from each litter) of purebred LW and EHL sows from two neighbouring pig breeding farms in Changzhou, Jiangsu Province, China, were slaughtered at 25 days of age just before weaning. The subcutaneous fat was taken and immediately placed into liquid nitrogen and stored at $-80^{\circ} \mathrm{C}$. The slaughter and sampling procedures complied with the "Regulation regarding the Management and Treatment of Experimental Animals" (2008) no. 45 set by Jiangsu Provincial People's Government. The experiment protocol was specifically approved by the Animal Ethics Committee of Nanjing Agricultural University.

\subsection{RNA extraction and reverse transcription (RT)}

Total RNA was extracted using Trizol Plus RNA Purification Kit (Invitrogen, Thermo Fisher Scientific Inc., Waltham, MA, USA). Concentration of the extracted RNA was measured using NanoDrop 1000 Spectrophotometer. Ratios of absorption $(260 / 280 \mathrm{~nm})$ of all preparations were between 1.8 and 2.0. RNA integrity was confirmed by agarose electrophoresis and DNA contamination was examined by PCR. Reverse transcription was performed using the total RNA $(2 \mu \mathrm{g})$ in a final volume of $25 \mu \mathrm{L}$ containing $1 \times$ RT-buffer, $100 \mathrm{U}$ Moloney Murine Leukemia Virus reverse transcriptase (M-MLV) (Promega Corp., Fitchburg, WI, USA), 8 U RNase inhibitor (Promega), $5.3 \mu \mathrm{mol} \mathrm{L}^{-1}$ random hexamer primers and $0.8 \mu \mathrm{mol} \mathrm{L}^{-1}$ dNTP (TaKaRa Bio Inc., Otsu, Shiga, Japan).

\subsection{PCR}

PCR was performed in Gene Amp PCR system (PerkinElmer Inc., Waltham, MA, USA). $2 \mu \mathrm{L}$ RT product was used for general PCR in a final volume of $50 \mu \mathrm{L}$ containing 2.5 U LA Taq (TaKaRa, Japan), $5 \mu \mathrm{L} 10 \times \mathrm{LA}$ PCR Buffer, $400 \mu \mathrm{M}$ dNTPs, $36.5 \mu \mathrm{L} \mathrm{ddH}_{2} \mathrm{O}$ and $0.2 \mu \mathrm{M}$ forward and reverse primers for ZAG (forward primes: 5'-CCCAGCCATTCCCATAACTA-3', reverse primers: 5'CCCAGTGCTGGCACTCTTCT-3'), using a program of 35 cycles $\left(30 \mathrm{~s}\right.$ at $95^{\circ} \mathrm{C}, 30 \mathrm{~s}$ at $58^{\circ} \mathrm{C}, 30 \mathrm{~s}$ at $\left.72^{\circ} \mathrm{C}\right)$ and a final step of $10 \mathrm{~min}$ at $72^{\circ} \mathrm{C}$. The obtained PCR products were analysed on 2\% agarose gel and purified with an AxyPrep DNA Gel Extraction Kit (Axygen Scientific, Inc., Hangzhou, China) and then sequenced.

\subsection{Quantitative PCR}

Quantitative PCR was performed with Mx3000P (Stratagene, Agilent Technologies, Inc., Santa Clara, CA, USA). Mock RT and no template controls (NTC) were set to monitor the possible contamination of genomic DNA both at RT and PCR. The pooled sample made by mixing equal quantities of total RT products (cDNA) from all samples was used to 
optimize PCR conditions and tailor the standard curves for each target gene. Melting curves were performed to ensure a single specific PCR product for each gene. $2 \mu \mathrm{L}$ of the eightfold dilution of RT product were used for RT-PCR in a final volume of $25 \mu \mathrm{L}$ containing $12.5 \mu \mathrm{L}$ SYBR Green Real-time PCR Master Mix (TaKaRa, Japan) and $0.4 \mu \mathrm{M}$ of each forward and reverse primers for ZAG, HSL, PPAR $\gamma, \mathrm{C} / \mathrm{EBP} \beta$, $\mathrm{TNF} \alpha, \beta 3-\mathrm{AR}, \mathrm{ATGL}, \mathrm{UCP} 2$ and $\mathrm{CPT} 1$ genes (sequences of primers were shown in Table 1). All samples were normalized with the reference gene $18 \mathrm{~S}$ rRNA. The PCR products for each gene were sent for sequencing to verify accuracy (Haojia Biotech, Ltd., Shanghai, China). The reported sequences exactly matched those published in GenBank. The method of $2^{-\mathrm{Ct}}$ was used to analyse the real-time PCR data. All samples were included in the same run of RT-PCR and repeated in triplicates.

\subsection{Protein extraction and western blot analysis}

Total protein was extracted from $500 \mathrm{mg}$ of frozen subcutaneous fat in $1 \mathrm{~mL}$ lysis buffer $\left(150 \mathrm{mmol} \mathrm{L}^{-1} \mathrm{NaCl}\right.$, $10 \mathrm{mmol} \mathrm{L}^{-1}$ Tris-HCl, $5 \mathrm{mmol} \mathrm{L}^{-1}$ EDTA, $1 \%$ Triton X100 and $0.1 \%$ SDS (Sinopharm Chemical Reagent Co., Ltd., Shanghai, China). The protease inhibitor cocktail (Roche Applied Science) was added according to the manufacturer's instructions. The protein concentration was measured with the BCA Protein Assay Kit (Pierce, Rockford, IL, USA) according to the manufacturer's instructions. Thirty micrograms of protein extract were used for electrophoresis on a $12 \%$ SDS-PAGE gel. western blot analyses for ZAG (13399-1-AP, Proteintech Group, USA, diluted 1:5000), C/EBP $\beta$ (sc-150x, Santa Cruz, USA, diluted $1: 2000$ ), UCP2 (11081-1-AP, Proteintech group, USA, diluted 1:5000) and PPAR $\gamma$ (BS1587, Bioworld, China, diluted 1:1000) were carried out according to the recommended protocols provided by the manufacturers. $\beta$-actin (AP0060, Bioworld, USA, diluted $1: 6000$ ) was used as a reference in the western blot analyses.

\subsection{Lipase (including HSL and ATGL) activity assay}

$500 \mathrm{mg}$ frozen subcutaneous fat in $1 \mathrm{~mL}$ homogenization buffer $\left(0.1 \mathrm{mmol} \mathrm{L}^{-1} \mathrm{~K}^{+}\right.$-PBS containing $1 \mathrm{mmol} \mathrm{L}^{-1}$ $\mathrm{MgCl}_{2}, 1 \mathrm{mmol} \mathrm{L}^{-1}$ DTT and $1 \mathrm{mmol} \mathrm{L}^{-1}$ EDTA) was homogenized in ice for $30 \mathrm{~min}$ and then centrifuged for $10 \mathrm{~min}$ at $12000 \times g$ at $4{ }^{\circ} \mathrm{C}$. The protein concentration of supernatants was measured with the BCA Protein Assay Kit (Pierce Chemical Corp., Rockford, USA). Triolein without glycerin was used as substrate which can be hydrolysed to glycerol by the two enzymes, HSL and ATGL. The supernatants together with prepared triolein were incubated for $1 \mathrm{~h}$ at $37^{\circ} \mathrm{C}$. The lipases in supernatants activate the lipolytic degradation of the triolein emulsion. The released glycerol was measured with a commercial kit (Applygen, China). To fit the activities of the enzymes to the linear range of stan-
Table 1. The primer sequences of the target genes.

\begin{tabular}{|c|c|c|}
\hline Target genes & $\begin{array}{l}\text { PCR pro- } \\
\text { ducts, bp }\end{array}$ & Primer sequences \\
\hline ZAG & 106 & $\begin{array}{l}\text { F: 5' -gggcaggtttggetgtgag-3' } \\
\text { R: 5'-ggctgggatttcttgttg-3' }\end{array}$ \\
\hline $\operatorname{PPAR} \gamma$ & 210 & $\begin{array}{l}\text { F: 5'-gcccttcaccactgttgatt-3' } \\
\text { R: 5'-gagttggaaggctcttcgtg-3' }\end{array}$ \\
\hline $\mathrm{TNF} \alpha$ & 160 & $\begin{array}{l}\text { F: 5'-ccacgctcttctgcctactgc-3', } \\
\text { R: 5'-tcggcttgacattggctacaa-3' }\end{array}$ \\
\hline$\beta 3-\mathrm{AR}$ & 149 & $\begin{array}{l}\text { F: 5'-gctggttgccettctttgtgg-3' } \\
\text { R: 5'-gcgaaagtctgggctgtggc-3' }\end{array}$ \\
\hline HSL & 84 & $\begin{array}{l}\text { F: 5'-accctcggctgtcaacttctt-3' } \\
\text { R: 5'-tcctccttggtgctaatctcgt-3' }\end{array}$ \\
\hline FAS & 206 & $\begin{array}{l}\text { F: 5'-gtcctgctgaagcctaactc-3' } \\
\text { R: 5'-tccttggaaccgtctgtg-3' }\end{array}$ \\
\hline ATGL & 153 & $\begin{array}{l}\text { F: 5'-acctgtccaacctgctgc-3' } \\
\text { R: 5'-gcctgtctgctcctttatcca-3' }\end{array}$ \\
\hline $\mathrm{C} / \mathrm{EBP} \beta$ & 158 & $\begin{array}{l}\text { F: 5' -gacaagcacagcgacgagta-3' } \\
\text { R: 5'-agctgctccaccttcttctg-3' }\end{array}$ \\
\hline $\mathrm{UCP} 2$ & 111 & $\begin{array}{l}\text { F: 5'- tcacccaatgtcgctcgta-3' } \\
\text { R: 5'-gcagggaaggtcatctgtca-3' }\end{array}$ \\
\hline CPT1 & 126 & $\begin{array}{l}\text { F: 5'- actgagaccgtgcgttcct-3' } \\
\text { R: 5' -cagatgctggtgcttttcg-3' }\end{array}$ \\
\hline $18 \mathrm{~S}$ & 122 & $\begin{array}{l}\text { F: 5' -cccacggaatcgagaaagag-3' } \\
\text { R: 5'-ttgacggaagggcacca-3' }\end{array}$ \\
\hline
\end{tabular}

dard curves constructed with pure enzymes, all samples were measured in duplicates at appropriate dilutions. The activity of lipases is expressed as nanomoles released glycerol per milligram protein per hour.

\subsection{Statistical analyses}

All data are presented as mean \pm standard error. Statistical analyses were carried out with SPSS 13.0 for Windows. The differences were analysed using a $t$ test for independent samples. A $P$ value of less than 0.05 was considered to be significant.

\section{Results}

\subsection{Body weight and serum triglyceride concentration between LW and EHL pigs}

The body weight of LW and EHL pigs at weaning age was $8.10 \pm 0.34$ and $4.08 \pm 0.25 \mathrm{~kg}$, respectively. The serum triglyceride content of LW and EHL pigs was $0.29 \pm 0.03$ and $0.62 \pm 0.12 \mathrm{mmol} \mathrm{L}^{-1}$, respectively. Both the body 


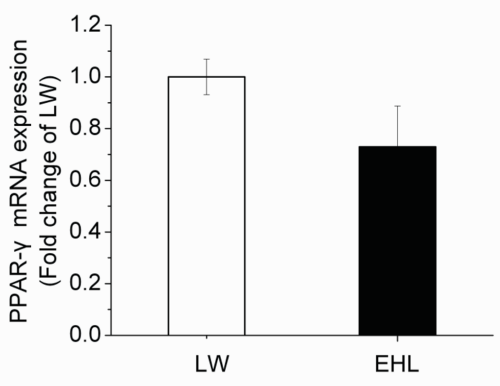

C

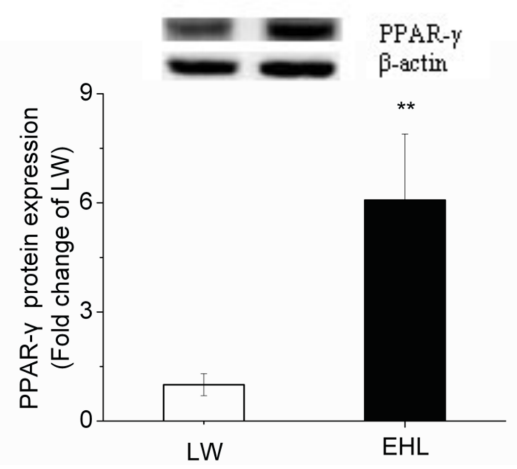

B

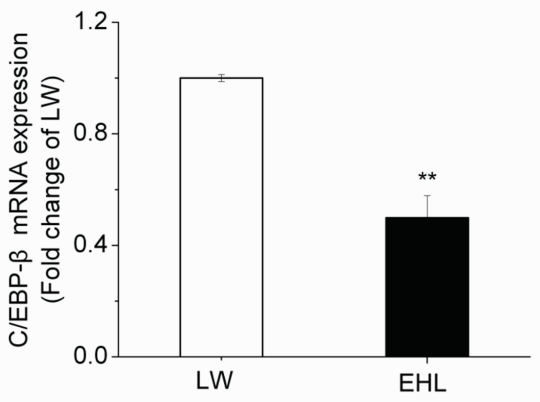

D

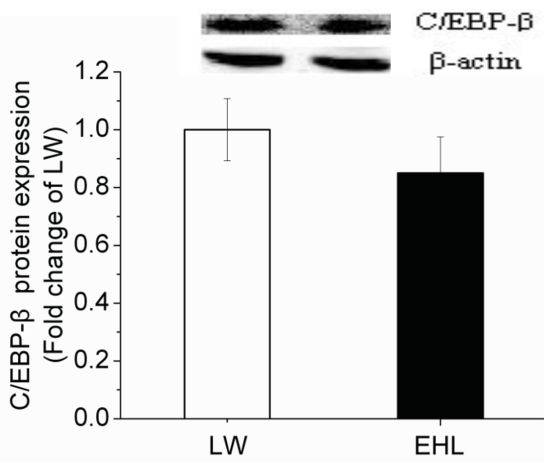

Figure 1. mRNA and protein expression of genes involved in adipogenesis in the subcutaneous fat of LW and EHL pigs. (a) PPAR $\gamma$ mRNA expression, (b) $\mathrm{C} / \mathrm{EBP} \beta$ mRNA expression, (c) PPAR $\gamma$ protein expression, (d) C/EBP $\beta$ protein expression. The values shown represent the mean \pm standard error, $n=6$; $* * P<0.01$ vs. LW.

weight and serum triglyceride concentration demonstrated a significant breed difference $(P<0.05)$.

\subsection{Lipogenesis- and lipolysis-related gene expression in the subcutaneous fat between LW and EHL pigs}

Though C/EBP $\beta$ mRNA expression was significantly lower $(P<0.01)$ in the subcutaneous fat of EHL than in that of LW pigs; the protein expression demonstrated no difference. PPAR $\gamma$ mRNA expression showed no difference between the two breeds, while its protein level was significantly higher $(P<0.01)$ in the subcutaneous fat of EHL than in that of LW pigs (Fig. 1).

The mRNA expression of HSL and ATGL was significantly lower $(P<0.01)$ in the subcutaneous fat of EHL than in that of LW pigs (Fig. 2). The lipases (including HSL and ATGL) activity was also significantly lower $(P<0.05)$ in the subcutaneous fat of EHL than in that LW pigs (Fig. 2). mRNA expression of CPT1 and UCP2, two key genes involved in fatty acid oxidation, was significantly lower $(P<0.05)$ in the subcutaneous fat tissue of EHL than that of LW pigs. Furthermore, UCP2 protein level was also significantly lower $(P<0.01)$ in the subcutaneous fat of EHL than that of LW pigs (Fig. 3).

\subsection{Porcine ZAG gene sequencing and expression}

In the present study, we cloned the nucleotide sequence containing the complete open reading frame (ORF) of porcine ZAG with $1090 \mathrm{bp}$. The ORF sequences are conservative between species. MegAlign software (DNASTAR, Inc., Madison, WI, USA) was used to compare the homology of ZAG. The results showed that porcine ZAG gene nucleotide sequence possesses $82.2 \%$ homology with cattle and $69.5 \%$ homology with mice, respectively. Both the mRNA and protein expression of ZAG in the subcutaneous fat of EHL was significantly lower $(P<0.01)$ than that of LW pigs (Fig. 4$)$.

\subsection{TNF $\alpha, \beta 3-A R$ mRNA expression in the subcutaneous fat between LW and EHL pigs}

The expression of $\beta 3$-AR mRNA in subcutaneous fat of EHL pigs was significantly higher $(P<0.01)$ than that of $\mathrm{LW}$ pigs. No difference was observed in the expression of TNF $\alpha$ between the two breeds of pigs (Fig. 5).

\section{Discussion}

The EHL pig is a famous Chinese indigenous pig breed with high reproductive traits and meat quality, similar to its close relative the Meishan (MS) pig, whereas the LW pig is a lean type of pig. Concerning the fat deposition between these 
A

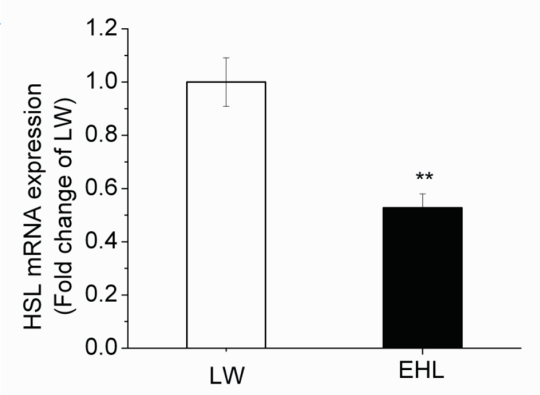

C

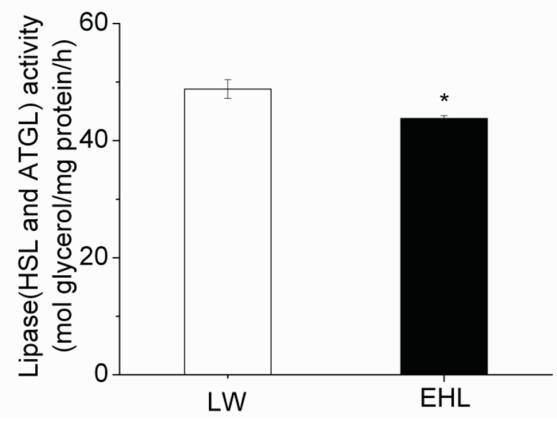

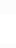

B

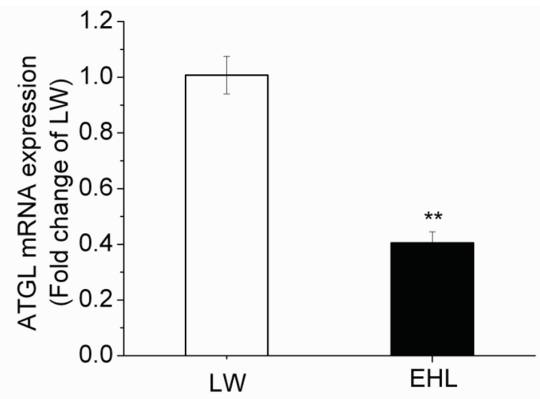

Figure 2. mRNA and protein expression of genes involved in lipolysis and lipases activity in the subcutaneous fat of LW and EHL pigs The values shown represent the mean \pm standard error, $n=6$; $* P<0.05$ vs. LW; $* * P<0.01$ vs. LW. (a) HSL mRNA expression, (b) ATGL mRNA expression and (c) Lipases activity (HSL and ATGL).

A

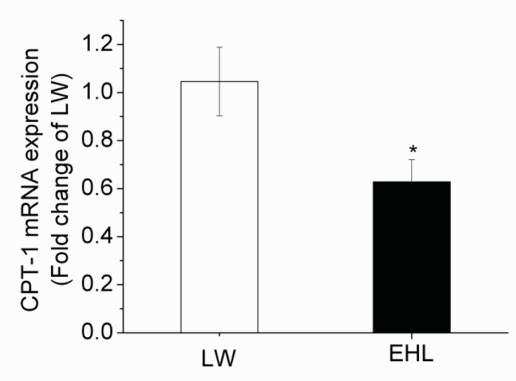

C

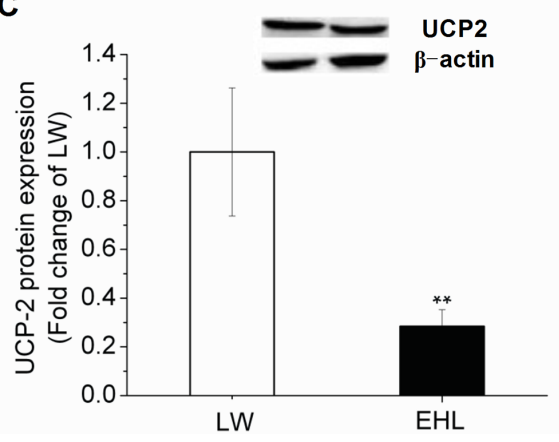

B

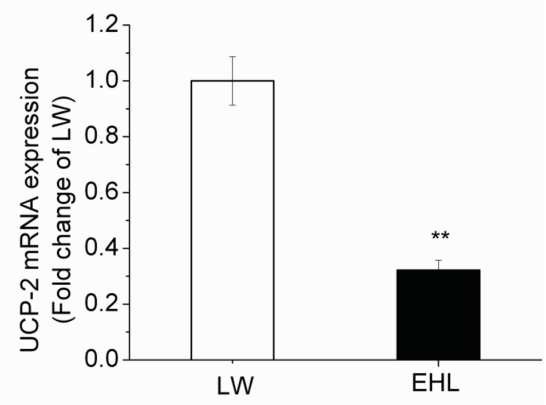

Figure 3. mRNA and protein expression of genes related to energy metabolism in the subcutaneous fat of LW and EHL pigs. (a) CPT1 mRNA expression, (b) UCP2 mRNA expression and (c) UCP2 protein expression. The values shown represent the mean \pm standard error, $n=6$; $* P<0.05$ vs. $\mathrm{LW} ; * * P<0.01$ vs. $\mathrm{LW}$. 


\begin{tabular}{|c|c|c|c|c|c|c|c|c|c|c|c|}
\hline \multirow[t]{2}{*}{ A } & \multicolumn{10}{|c|}{ Percent Identity } & \\
\hline & & 1 & 2 & 3 & 4 & 5 & 6 & 7 & 8 & & \\
\hline \multirow{9}{*}{ 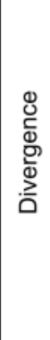 } & 1 & & 75.7 & 74.0 & 73.5 & 68.1 & 74.1 & 69.0 & 82.2 & 1 & Bos taurus \\
\hline & 2 & 24.0 & & 73.2 & 71.7 & 68.0 & 73.4 & 68.4 & 73.8 & 2 & Canis lupus familiaris \\
\hline & 3 & 26.3 & 28.7 & & 94.9 & 68.1 & 99.3 & 69.4 & 73.1 & 3 & Homo sapiens \\
\hline & 4 & 26.6 & 30.1 & 5.2 & & 68.0 & 95.0 & 68.9 & 71.9 & 4 & Macaca mulatta \\
\hline & 5 & 33.0 & 32.1 & 32.5 & 32.9 & & 68.2 & 92.0 & 69.5 & 5 & Mus musculus \\
\hline & 6 & 26.1 & 28.6 & 0.7 & 5.1 & 32.3 & & 69.6 & 73.1 & 6 & Pan troglodytes \\
\hline & 7 & 32.3 & 33.2 & 30.9 & 32.2 & 7.6 & 30.9 & & 70.6 & 7 & Rattus norvegicus \\
\hline & 8 & 17.4 & 25.4 & 26.3 & 27.5 & 31.9 & 26.2 & 30.4 & & 8 & Pigs \\
\hline & & 1 & 2 & 3 & 4 & 5 & 6 & 7 & 8 & & \\
\hline
\end{tabular}

\section{B}

CCCCGGACTCATTCATCTGCTCCGAGCTCCAGGGTTCTGGGGAAGTCTGGAAACTTCC CAGCCAGGAACGTGGGGCACAATGGCACCTGTCCTGCTGCCCCTGCTGCTCCTTTTGG GCCCTGCAGTCCCCAAGGAGACCCAAACTGGGCCTTACACTCTGAGCTTCCTCTACAC CGGGGCTGTCCAGGCCCGGGGAAAGGCTTCCCCAGCTTTCAGGCCATGGCCTACCTCAAT GACCAGCCCTTCTTCCGCTACGAGAGCGATGGCAGGAAGGCTGAGCCCCTGGGCCCCT GGAGCCAGGTGGAAGGGATGGAGGACTGGGAAAAGGAGAGCGAGCTTCAGAAGGCC AGGGAGGACATCTTCATGGCGACCCTGAGAGACATCATGGACTATTACAAGGACAGAC AAGGGTCGCACACCTTTCAGGGCAGGTTTGGCTGTGAGCTCCGGAACGACCAGCGCC AGGCAGCGTTCTGGAGGTACGCCTACGACGGTCGCGACTTCATCGAGTTCAACAAAG AAATCCCAGCCTGGGGTGGCTCTGGACCCAGCAGCCGTGAACACCAAGCTGAAGTGGG AGGCCGAAGCGGTCTACGTGCAGCGGGCCAAGGCCTACCTGGAGGAGGAGTGTCCGG GGATGCTGCGGAGGTACCTGGAACACGTCAGGGGCCACCTGGACCGGCAAGCCCCTC CCTCCGTGTCGATCACCCGCCACGTGGCCCCCAGGACAGAACGGGACCCTCAAGTGCC TGGCCTATGACTTCTACCCAGGAAGAATCGGTCTGCGCTGGACTGGCGCTGGTGGAGC ACAAGAGGCTGAGTCTGGGGGAGACGTTCTTCCCAGTGGAAACGGCTCTTACCAGTC CTGGGTGGTGGTGGGGGTCCCCCCTCAGGACAGAGCCCCTCACICGTGCCACGTGGAG CACAGCAGCCTGGCCCAGCCCCTCACTGTCCCTTGGGCAGGGCTGCAAGAACTGAGG GTGGAAGGCAACATTGGGACTCetgCCCAGTACGTGCCCTTGCTTTTGGACAGGAACCA TGTGAACTCTGGCAATTCCAGCCAAAGCAAAAAAAACAAGCCCCACAAGC

C

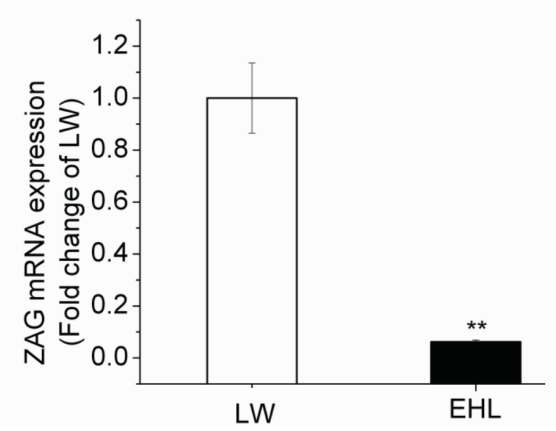

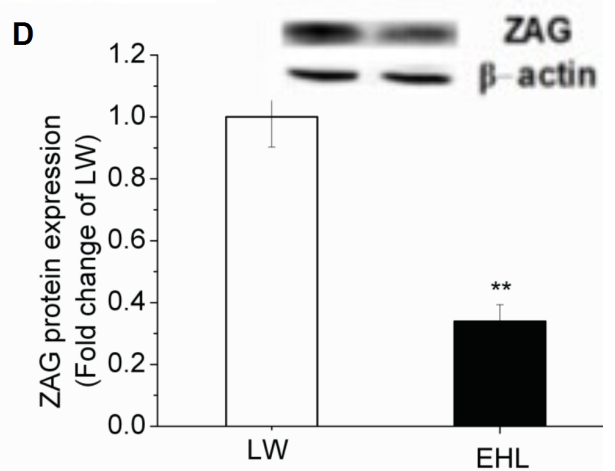

Figure 4. Porcine ZAG gene sequencing and its mRNA and protein expression between LW and EHL pigs. (a) Homology analysis, (b) porcine ZAG cDNA sequence, (c) ZAG mRNA expression and (d) ZAG protein expression. The values shown represent the mean \pm standard error, $n=6 ; * * P<0.01$ vs. LW.

two breeds, previous studies suggested that adipose tissue development occurs much earlier in MS than in LW pigs (Mourot et al., 1996), and preadipocyte proliferation also demonstrated the breed difference in vitro (Gerfault et al., 1999). Recent studies have shown that the quantitative trait locus (QTL) for the lipid metabolic characteristics is in both two breeds located on chromosome 7 (Demars et al., 2007; Gondret et al., 2012). In the present study, we demonstrated that though the body weight of the EHL pig is only half of LW pigs, the serum triglyceride level in EHL pigs is significantly higher compared with LW pigs. Additionally, a significant difference was also observed in both adipogenesis- and lipolysis-related gene expressions between EHL and LW piglets at weaning age.

Regarding the adipogenesis, $\mathrm{C} / \mathrm{EBP} \beta$ and $\operatorname{PPAR} \gamma$ are well-established key transcription factors. PPAR $\gamma$ could stimulate the differentiation from preadipocytes into mature adipocytes and is closely associated with fat formation. PPAR $\gamma$-deficient mice exhibited smaller adipocytes and decreased fat mass compared with wild mice (Kubota et al., 1994). C/EBP $\beta$ is also known to directly influence adipocytes' development (Rosen et al., 2000). It could lead preadipocytes to the proliferative stage and activates $\operatorname{PPAR} \gamma$ to promote the differentiation of adipocytes (Devine et al., 1999). C/EBP $\beta$ also could make other cells turn into 
A

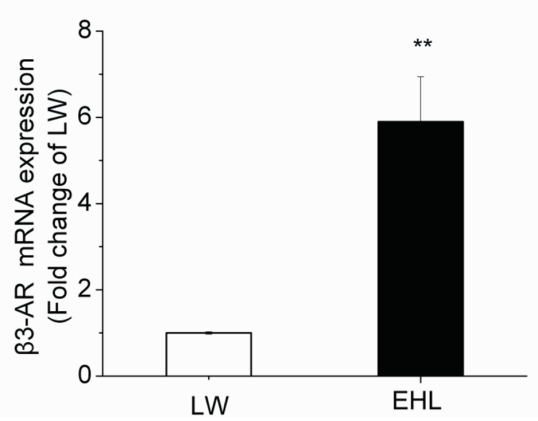

B

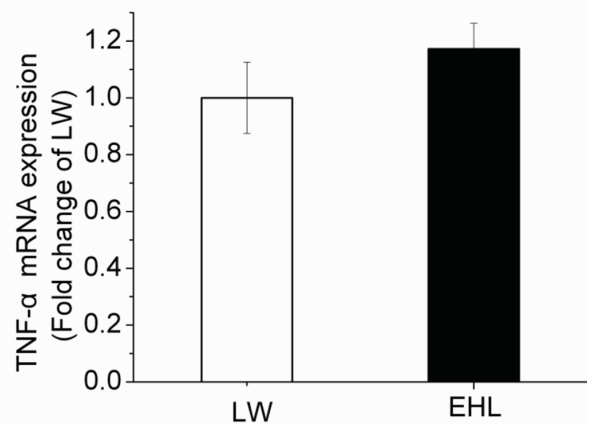

Figure 5. mRNA expression of TNF $\alpha$ and $\beta 3$-AR in subcutaneous fat of LW and EHL pigs. (a) TNF $\alpha$ mRNA expression and (b) $\beta 3$-AR mRNA expression. The values shown represent the mean \pm standard error, $n=6$; ${ }^{*} P<0.01 \mathrm{vs}$. LW.

adipocytes (Wu et al., 1995). In the present study, though the mRNA expression of $\mathrm{C} / \mathrm{EBP} \beta$ decreased, the protein concentration demonstrated no significant difference. The protein level of PPAR $\gamma$ was significantly higher in EHL than in LW pigs. PPAR $\gamma$ could regulate the expression of lipid metabolism-related genes to promote the synthesis of triglycerides in adipocytes and could cause the cell volume increase (Vidal-Puig et al., 1997). Additionally, PPAR $\gamma$ could also inhibit the expression of genes involved in lipolysis and fatty acid release (Prusty et al., 2002). From our study we infer that EHL pigs may possess greater capability for adipogenesis.

For the lipolysis, the mobilization of triglyceride in fat cells is mainly dependent on HSL and ATGL. ATGL could hydrolyse triglycerides and HSL could hydrolyse both triglycerides and diglycerides. Both of them are the limited enzymes of triglyceride hydrolysis process. The present study showed that EHL pigs had significantly lower HSL and ATGL mRNA expression than LW pigs, and the lipase activity of the EHL pig was also lower than that of the LW pigs. The results showed that EHL pigs lesser capability for lipolysis than LW pigs. CPT is a limited enzyme of fatty acid $\beta$ oxidation. Intensive research has revealed a critical role for $\mathrm{UCP}$ in the control of mitochondrial reactive oxygen species production and in various physiological events such as obesity and diabetes (Rosen et al., 2000; Zhang et al., 2001). Elevated UCP expression could promote the utilization of the free fatty acids and could translate their energy into heat production (Ceperuelo-Mallafré et al., 2009). In the present study, the mRNA expressions of CPT1 and UCP2 were significantly lower in the subcutaneous fat of EHL than in that of LW pigs. The level of UCP2 protein decreased significantly in EHL compared with LW pigs. It seems that the breed difference of lipid deposition has existed at early postnatal age. Similar to breed lipid metabolism differences at the finishing stage (Li et al., 2008a, b), the two breeds demonstrated a big difference in lipid metabolism at weaning age. EHL pigs possess significantly greater capability for adipogenesis and the lesser capability for lipolysis and utilization compared with LW pigs.

ZAG is newly defined as a kind of adipokine. A previous study has demonstrated that elevated ZAG could decrease blood glucose, triglyceride and free fatty acid levels in mice compared with the control group (Ceperuelo-Mallafré et al., 2009). Furthermore, there is a clear correlation between $Z A G$ content and body weight reduction (Todorov et al., 1998). Both body weight and epididymal fat were reduced in ZAG overexpressive mice (Gong et al., 2009). An injection of human ZAG could increase over-fed mice's utilization of sugar intake, the rate of glucose metabolism and lipid oxidation in heart, brain and brown fat tissue (Russell and Tisdale, 2002). There is growing evidence pointing to ZAG as a potential therapeutic target for obesity (Gong et al., 2009; Gao et al., 2010). However, until now, there has been no report on ZAG in pigs. In the present study, we first cloned a part of porcine ZAG cDNA sequence including ORF, and the nucleotide sequence homology analysis showed that porcine ZAG gene possesses the highest homology with cattle $(82.2 \%)$. Furthermore, both mRNA expression (almost 10 times higher) and protein level (2 times higher) of ZAG were significantly lower in EHL compared with LW pigs. The present study suggests that ZAG expressed in porcine adipose tissue, and its expression existed great breed difference at the early postnatal age. It may directly correlate with the fat deposition in pigs.

It has been demonstrated that ZAG bounds to $\beta 3$-AR and activated GTP-dependent adenylate cyclase in the membrane as well as intracellular cAMP level and HSL activity (Russell et al., 2002, 2004). The effect of ZAG can be blocked by $\beta 3$-AR antagonist SR59230 (Russell et al., 2002). In the present study, $\beta 3$-AR mRNA expression in white adipose tissue of EHL was significantly higher than that of LW pigs. This may be due to the low content of ZAG. It has been shown that the proinflammatory cytokine TNF $\alpha$ decreased in a dose-dependent manner after ZAG expression (Bao et al., 2005), whereas in the present study $\mathrm{TNF} \alpha$ gene expres- 
sion demonstrated no significant difference between the two breeds. Regardless, it needs further study to better understand the pathway of ZAG in porcine lipid metabolism.

In conclusion, EHL and LW pigs demonstrated a significant breed difference in lipid metabolism at early postnatal age. EHL pigs showed greater capability for lipid synthesis and lower lipid mobilization compared with LW pigs. ZAG may be an important adipokine involved in the formation of breed-specific fat deposition.

Acknowledgements. This study was supported by the $\mathrm{Na}-$ tional Basic Research Program of China (2012CB124703), the Special Fund for Agro-scientific Research in the Public Interest (201003011), the Program for New Century Excellent Talents in University (NCET-12-0889) and the Priority Academic Program Development of Jiangsu Higher Education Institutions.

Edited by: K. Wimmers

Reviewed by: two anonymous referees

\section{References}

Bao, Y., Bing, C., Hunter, L., Jenkins, J. R., Wabitsch, M., and Trayhurn, P.: Zinc- $\alpha 2$-glycoprotein, a lipid mobilizing factor, is expressed and secreted by human (SGBS) adipocytes, FEBS Lett., 579, 41-47, 2005.

Bing, C., Bao, Y., Jenkins, J., Sanders, P., Manieri, M., Cinti, S., Tisdale, M. J., and Trayhurn, P.: Zinc- $\alpha 2$-glycoprotein, a lipid mobilizing factor, is expressed in adipocytes and is up-regulated in mice with cancer cachexia, P. Natl. Acad. Sci. USA, 101, 25002505, 2004.

Ceperuelo-Mallafré, V., Näf, S., Escoté, X., Caubet, E., Gomez, J. M., Miranda, M., Chacon, M. R., Gonzalez-Clemente, J. M., Gallart, L., Gutierrez, C., and Vendrell, J.: Circulating and Adipose Tissue Gene Expression of Zinc- $\alpha 2$-Glycoprotein in Obesity: Its Relationship with Adipokine and Lipolytic Gene Markers in Subcutaneous and Visceral Fat, J. Clin. Endocrinol. Metab., 94, 5062-5069, 2009.

Dahlman, I., Kaaman, M., Olsson, T., Tan, G. D., Bickerton, A. S. T., Wåhlén, K., Andersson, J., Nordström, E. A., Blomqvist, L., Sjögren, A., Forsgren, M., Attersand, A., and Arner, P.: A Unique Role of Monocyte Chemoattractant Protein 1 among Chemokines in Adipose Tissue of Obese Subjects, J. Clin. Endocrinol. Metab., 90, 5834-5840, 2005.

Darlington, G. J., Ross, S. E., and MacDougald, O. A.: The role of C/EBP genes in adipocyte differentiation, J. Biol. Chem., 273, 30057-30060, 1998.

Demars, J., Riquet, J., Sanchez, M. P., Billon, Y., Hocquette, J. F., Lebret, B., Iannuccelli, N., Bidanel, J. P., Milan, D., and Gondret, F.: Metabolic and histochemical characteristics of fat and muscle tissues in homozygous or heterozygous pigs for the body composition QTL located on chromosome 7, Physiol. Genomics, 30, 232-241, 2007.

Devine, J. H., Eubank, D. W., Clouthier, D. E., Tontonoz, P., Spiegelman, B. M., Hammer, R. E., and Beale, E. G.: Adipose Expression of the Phosphoenolpyruvate Carboxykinase Promoter Requires Peroxisome Proliferator-activated Receptor $\gamma$ and 9-cis-Retinoic Acid Receptor Binding to an Adipocytespecific Enhancer in Vivo, J. Biol. Chem., 274, 13604-13612, 1999.

Fantuzzi, G.: Adipose tissue, adipokines, and inflammation, J. Allergy Clin. Immunol., 115, 911-919, 2005.

Gao, D., Trayhurn, P., and Bing, C.: Macrophage-secreted factors inhibit ZAG expression and secretion by human adipocytes, Mol. Cell Endocrinol., 325, 135-142, 2010.

Gerfault, V., Louveau, I., and Mourot, J.: The Effect of GH and IGF-I on Preadipocytes from Large White and Meishan Pigs in Primary Culture, Gen. Comp. Endocr., 114, 396-404, 1999.

Gondret, F., Riquet, J., Tacher, S., Demars, J., Sanchez, M. P., Billon, Y., Robic, A., Bidanel, J. P., and Milan, D.: Towards candidate genes affecting body fatness at the SSC7 QTL by expression analyses, J. Anim. Breed Genet., 129, 316-324, 2012.

Gong, F. Y., Zhang, S. J., Deng, J. Y., Zhu, H. J., Pan, H., Li, N. S., and Shi, Y. F.: Zinc- $\alpha 2$-glycoprotein is involved in regulation of body weight through inhibition of lipogenic enzymes in adipose tissue, Int. J. Obes., 33, 1023-1030, 2009.

Granneman, J. G., Moore, H. P. H., Granneman, R. L., Greenberg, A. S., Obin, M. S., and Zhu, Z.: Analysis of Lipolytic Protein Trafficking and Interactions in Adipocytes, J. Biol. Chem., 282, 5726-5735, 2007.

Gregoire, F. M., Smas, C. M., and Sul, H. S.: Understanding Adipocyte Differentiation, Physiol. Rev., 78, 783-809, 1998.

Guerre-Millo, M.: Adipose tissue and adipokines: for better or worse, Diabetes Metab., 30, 13-19, 2004.

Koh, Y. J., Park, B. H., Park, J. H., Han, J., Lee, I. K., Park, J. W., and Koh, G. Y.: Activation of PPAR $\gamma$ induces profound multilocularization of adipocytes in adult mouse white adipose tissues, Exp. Mol. Med., 41, 880-895, 2009.

Kubota, N., Terauchi, Y., Miki, H., Tamemoto, H., Yamauchi, T., Komeda, K., Satoh, S., Nakano, R., Ishii, C., Sugiyama, T., Eto, K., Tsubamoto, Y., Okuno, A., Murakami, K., Sekihara, H., Hasegawa, G., Naito, M., Toyoshima, Y., Tanaka, S., Shiota, K., Kitamura, T., Fujita, T., Ezaki, O., Aizawa, S., Nagai, R., Tobe, K., Kimura, S., and Kadowaki, T.: PPAR $\gamma$ Mediates HighFat Diet-Induced Adipocyte Hypertrophy and Insulin Resistance, Mol. Cell, 4, 597-609, 1994.

Li, M., Li, X., Zhu, L., Jiang, Y., and Tang, G.: [Developmental expression changes of specific genes in adipose tissue for different pig breeds by using pathway-focused microarray], Chinese J. Biotech., 24, 665-672, 2008a (in Chinese).

Li, M., Zhu, L., Li, X., Shuai, S., Teng, X., Xiao, H., Li, Q., Chen, L., Guo, Y., and Wang, J.: Expression profiling analysis for genes related to meat quality and carcass traits during postnatal development of backfat in two pig breeds, Sci. China Ser. C, 51, 718733, 2008b.

Li, Y., Li, H., Zhao, X., Li, N., and Wu, C.: UCP2 and 3 Deletion Screening and Distribution in 15 Pig Breeds, Biochem. Genet., 45, 103-111, 2007.

Mourot, J., Kouba, M., and Bonneau, M.: Comparative study of in vitro lipogenesis in various adipose tissue in the growing meishan pig: Comparison with the large white pig (Sus domesticus), Comp. Biochem. Phys. B, 115, 383-388, 1996.

Mracek, T., Ding, Q., Tzanavari, T., Kos, K., Pinkney, J., Wilding, J., Trayhurn, P., and Bing, C.: The adipokine zinc- $\alpha 2-$ glycoprotein (ZAG) is downregulated with fat mass expansion in obesity, Clin. Endocrinol., 72, 334-341, 2010. 
Nakajima, I., Oe, M., Ojima, K., Muroya, S., Shibata, M., and Chikuni, K.: Cellularity of developing subcutaneous adipose tissue in Landrace and Meishan pigs: Adipocyte size differences between two breeds, Anim. Sci. J., 82, 144-149, 2011.

Prusty, D., Park, B. H., Davis, K. E., and Farmer, S. R.: Activation of MEK/ERK Signaling Promotes Adipogenesis by Enhancing Peroxisome Proliferator-activated Receptor $\gamma(\operatorname{PPAR} \gamma)$ and $\mathrm{C} / \mathrm{EBP} \alpha$ Gene Expression during the Differentiation of 3T3-L1 Preadipocytes, J. Biol. Chem., 277, 46226-46232, 2002.

Quintanilla, R., Milan, D., and Bidanel, J. P.: A further look at quantitative trait loci affecting growth and fatness in a cross between Meishan and Large White pig populations, Genet. Sel. Evol., 34, 193-210, 2002.

Rolli, V., Radosavljevc, M., Astier, V., Macquin, C., Castan-Laurell, I., Visentin, V., Guigné, C., Carpéné, C., Valet, P., Gilfillan, S., and Bahram, S.: Lipolysis is altered in MHC class I zinc- $\alpha 2-$ glycoprotein deficient mice, FEBS Lett., 581, 394-400, 2007.

Rosen, E. D., Walkey, C. J., Puigserver, P., and Spiegelman, B. M.: Transcriptional regulation of adipogenesis, Genes. Dev., 14, 1293-1307, 2000.

Russell, S. T. and Tisdale, M. J.: Effect of a tumour-derived lipidmobilising factor on glucose and lipid metabolism in vivo, Br. J. Cancer., 87, 580-584, 2002.

Russell, S. T., Hirai, K., and Tisdale, M. J.: Role of $\beta 3$-adrenergic receptors in the action of a tumour lipid mobilizing factor, Br. J. Cancer., 86, 424-428, 2002.

Russell, S. T., Zimmerman, T. P., Domin, B. A., and Tisdale, M. J.: Induction of lipolysis in vitro and loss of body fat in vivo by zinc$\alpha$ 2-glycoprotein, BBA Mol. Cell. Biol. L., 1636, 59-68, 2004.

Schweiger, M., Schreiber, R., Haemmerle, G., Lass, A., Fledelius, C., Jacobsen, P., Tornqvist, H., Zechner, R., and Zimmermann, R.: Adipose Triglyceride Lipase and Hormone-sensitive Lipase Are the Major Enzymes in Adipose Tissue Triacylglycerol Catabolism, J. Biol. Chem., 281, 40236-40241, 2006.
Singla, P., Bardoloi, A., and Parkash, A. A.: Metabolic effects of obesity: A review, World J. Diabetes, 1, 76-88, 2010.

Spurlock, M. E. and Gabler, N. K.: The Development of Porcine Models of Obesity and the Metabolic Syndrome, J. Nutr., 138, 397-402, 2008.

Todorov, P. T., McDevitt, T. M., Meyer, D. J., Ueyama, H., Ohkubo, I., and Tisdale, M. J.: Purification and Characterization of a Tumor Lipid-mobilizing Factor, Cancer Res., 58, 2353-2358, 1998.

Vidal-Puig, A. J., Considine, R. V., Jimenez-Liñan, M., Werman, A., Pories, W. J., Caro, J. F., and Flier, J. S.: Peroxisome proliferator-activated receptor gene expression in human tissues. Effects of obesity, weight loss, and regulation by insulin and glucocorticoids, J. Clin. Invest., 99, 2416-2422, 1997.

Wei, W. H., Skinner, T. M., Anderson, J. A., Southwood, O. I., Plastow, G., Archibald, A. L., and Haley, C. S.: Mapping QTL in the porcine MHC region affecting fatness and growth traits in a Meishan/Large White composite population, Anim. Genet., 42, 83-85, 2011.

Wells, J. C. K.: The programming effects of early growth, Early Hum. Dev., 83, 743-748, 2007.

Wu, Z., Xie, Y., Bucher, N. L., and Farmer, S. R.: Conditional ectopic expression of C/EBP beta in NIH-3T3 cells induces PPAR gamma and stimulates adipogenesis, Genes. Dev. Oct., 9, 23502363, 1995.

Zhang, C. Y., Baffy, G., Perret, P., Krauss, S., Peroni, O., Grujic, D., Hagen, T., Vidal-Puig, A. J., Boss, O., Kim, Y. B., Zheng, X. X., Wheeler, M. B., Shulman, G. I., Chan, C. B., and Lowell, B. B.: Uncoupling Protein-2 Negatively Regulates Insulin Secretion and Is a Major Link between Obesity, $\beta$ Cell Dysfunction, and Type 2 Diabetes, Cell, 105, 745-755, 2001. 